\title{
Od kulture sebičnosti prema kulturi solidarnosti
}

\author{
Josip Jelenić*
}

\begin{abstract}
Sažetak
Autor promišlja pojavu u suvremenom društvu nazvanom kultura sebičnosti, koja je tijekom vremena, postala ideologija modernog čovjeka. Ideologija uvijek isključuje drugoga, različitoga, jer je riječ o jednosmjernomu, sebičnomu, djelovanju temeljenomu na dominaciji. Posljedica toga su podjele u društvu koje izazivaju trajne sukobe i koje nerijetko završavaju samouništenjem. Umjesto kulture sebičnosti, redovito temeljenoj na ideologiji, predlaže se kultura solidarnosti kao način života i rada za osobno i opće dobro. Riječ je o solidarnosti koja se izabire kao temeljna vrednota koja postaje načelo i obvezni način djelovanja. Solidarnost, a ne sebičnost, izriče društvenu ili relacijsku narav čovjeka.

Ključne riječi: sebičnost, kultura, solidarnost, sukobi, ideologija, opće dobro
\end{abstract}

\section{Uvod}

Odlučivši se promišljati odabranu temu, smatrao sam prikladnim spomenuti tvrdnju Paola Albanija kako glupost prožima sva područja ljudskog djelovanja (Albani, 2016, 28) što otvara prostor za razmišljanje o predloženom naslovu. Uostalom, nije li sebičnost posljedica ljudske gluposti? Matthijs van Boxel ide korak dalje i tvrdi kako je glupost utemeljujući element naše civilizacije sebičnosti (Boxel, 2008). Umberto Eco, predstavnik talijanske moderne, poistovjećuje sebičnjaka s glupanom i određuje ga kao onoga kojemu nedostaje logično (dakle, ne društveno) (Carriere i Eco, 2017). ${ }^{1}$ Postavlja se pitanje: nije li kultura sebičnosti izričaj ne-logičnosti, to jest ljudske gluposti i zlobe koja se očituje u svakodnevnoj praksi? Potvrdan odgovor uvodi u novo pitanje: je li moguće razmišljati logično o ne-logičnom ili ne-logičnosti? U svakom slučaju, tražeći odgovor na postavljena pitanja, treba izbjegavati logiku crno-bijelog. Jednako tako, ne upasti, prema Umbertu Ecu, u Owenov paradoks: »Svi su ljudi glupi (blesavi!), osim mene i tebe. No, iskreno govoreći, i ti si glup također « (Carriere i Eco, 2017, 173ss). U tom slučaju sebičnost je dovedena do savršenstva, do potpune isključi-

\footnotetext{
* Prof. dr. sc. Josip Jelenić, Papinsko sveučilište Gregoriana u Rimu. Adresa: Piazza della Pilotta 4, 00187 Rim, Italija. E-pošta: jelenic@unigre.it

1 Usp. osobito poglavalje Elogio dell'idiozia.
} 
vosti drugoga, što ni u kojem slučaju ne čini dio kulture koja se smatra skupom vrednota koje vode dobru. Michael Ignatieff primjećuje da je čovjek moderne platio najveću cijenu upravo »gubitkom zajedništva i susjedstva«, tj. otvorenosti prema drugima i za druge. Izgubio je smisao za drugog različitog, kao posljedicu sebičnosti, što rađa sukobima umjesto dijalogom (Michael, 2016, 7).

Danas je „moderno“ i „suvremeno“ govoriti o kulturi svega i svačega a da se pri tome ne vodi računa o njezinu sadržaju i naravi. Svjedoci smo inflacije kultura. Prije smo shvaćali i govorili o kulturi kao o nečem pozitivnom, o (pozitivnim) vrijednostima (vrednotama) ${ }^{2}$ koje su po sebi usmjerene i izriču dobro. ${ }^{3}$ Ako prihvatimo tu tvrdnju, tada neizravno zaključujemo kako sebičnost ne spada u kulturu jer nije pozitivna vrednota. Drugim riječima, besmisleno je govoriti i promicati kulturu sebičnosti, jer je ona usmjerena isključivo vlastitoj koristi, a ne dobru pojedinca i zajednice te kao takva ne može biti vrednota (koja čini bit kulture). Sebičnost isključuje drugoga, svodi ga na korisnu robu ili predmet, što je nespojivo s kulturom. Ipak, unatoč očitosti na pojmovnoj razini, sebičnost, kao dio kulture, postala je globalizirana praksa, što nas sili na ozbiljno promišljanje o njezinoj dinamici i imperativnoj (nasrtljivosti) nametljivosti. Drugim riječima, nalazimo se pred pojavom i izazovom koji se zove kultura sebičnosti. S teorijskog stajališta riječ je o dvama pojmovima, kulturi i sebičnosti, a s praktičnog stajališta riječ je o cjelini dvije vrste osobnog (i zajedničkog) ponašanja, kojima moramo odgonetnuti prirodu, sadržaj i cilj.

\section{Je li korisno biti sebičan? Priroda i sadržaj sebičnosti}

Čini se da nema ništa pogubnije za javni život od podmukle sebičnosti koja se prikriva pod različitim maskama i na svim razinama, osobnog i javnog života. Sebičnost je plod čovjekova izbora i uvjerenja kako treba živjeti samo za sebe. Druge vidi kao opasnost koja mu stalno prijeti jer homo homini lupus est. Sebičnost je istodobno i znak čovjekove slabosti. Budući da nema povjerenja ni u sebe ni u druge, sebičnjak trajno živi nad ponorom svoje nedovršenosti, uvijek spreman sukobiti se sa svima i svakim. Riječ je o zatvorenom krugu iz kojega, bilo pojedinac bilo društvene strukture, mogu izići samo uz iskreno i trajno osobno nastojanje i suradnju s milošću Božjom. U čemu se, dakle, sastoji priroda i sadržaj sebično-

2 Pretpostavljam najopćenitiju suglasnost o vrijednostima ili vrednotama kao pozitivnim stvarnostima. Istini za volju, danas ni u tome nije lako postići jednoglasnost.

3 Riječ kultura (od lat. collere) može biti shvaćena kao usavršavanje, oplemenjivanje, tj. »proces nastajanja duhovnih dobara i ljudskih [...] potreba« ili kao »sustav vrijednosti i sustav izraza, postupaka i standarda djelovanja u jednom društvu« (Bosanac i dr., 1977, s. v. kultura). Jednako tako vrijedno je naše pozornosti tumačenje kulture kao »vježbanje naših duhovnih sposobnosti po kojoj su one postavljene u uvjete da donose obilne i bolje plodove koje njihova naravna konstitucija dopušta«. To vježbanje je veoma blizu grčkoj riječi $\pi \alpha$ ısía, odgajanje, odgoj. Točnije odgajanje intelektualnih sposobnosti (Anon., 1977, s. v. cultura). Nadalje, treba razlikovati dobro od ugodnog. Redovito se ne podudaraju: dobro nije uvijek ugodno niti je ugodno uvijek dobro (Cucci, 2009, 77-100) S obzirom na vrstu, sadržaj i narav vrednota upućujem na talijanskog neoskolastičkog filozofa Battista Mondina (Mondin, 1985, 17-44). 
sti? Što je to što čovjeka navodi na isključivu usmjerenost na sebe u susretima s drugima, a što rađa negativnim i pogubnim posljedicama za osobni i javni život? ${ }^{4}$

Što je, dakle, sebičnost, ili bolje, što sebičnost nije? Tragajući za odgovorom, mislim kako sebičnost treba, prije svega, razlikovati od samopoštovanja. ${ }^{5}$ S psihologijskog stajališta, te dvije stvarnosti su nespojive, isključuju se. Prva (samopoštovanje) proizlazi iz ostvarivanja osobnosti (na svim razinama osobnog i društvenog života), dakle otvorenosti prema drugima, a druga je rezultat ili usamljenosti ili nesigurnosti ili nezasitne želje za imanjem i posjedovanjem (bilo stvari bilo osoba). U slučaju sebičnosti, dakle, riječ je o negativnom: ja postojim i djelujem isključivo kao zatvoreno središte oko kojega se sve kreće, sve i svakoga si podlažem na svim razinama razmišljanja i djelovanja. Samopoštovanje naprotiv otvorena je, ostvarivana, razmjerna sigurnost i samosvijest prema sebi i drugima (ili o sebi i drugima). ${ }^{6}$ Već iz dosad rečenog zaključuje se kako biti sebičan nije nešto apstraktno ni ograničeno samo na pojmovni svijet, nego se očituje i potvrđuje u konkretnom ponašanju prema drugim osobama ili prema zajednici. Drugim riječima, sebično ponašanje pomaže nam shvatiti pojam sebičnosti.

Ostajući na razini izbora i ponašanja, daljnje pitanje je: kako je moguća kultura sebičnosti — contradictio in terminis — ako je prvo pozitivno, a drugo negativno? Kultura se odnosi na vrednote i vrijednosti, po sebi pozitivne, koje čovjek birajući hoda prema dobru koje ga ispunjava i usmjerava (Mondin, 1985, 133142). ${ }^{7}$ Može li i sebičnost biti vrednota ili vrijednost? Ovisi o načinu shvaćanja kulture i sebičnosti, tj. o izboru vrednota. ${ }^{8}$ Odgovoriti na postavljena pitanja tim je teže što se danas sve češće govori o „zdravoj sebičnosti“, koja ne samo da je potrebna, nego bez nje, primjerice u ekonomiji, nema ni poduzetnosti ni napretka, a još manje dobiti. Treba biti oprezan i ne poistovjećivati poduzetnost sa sebičnošću i obrnuto. Istina, to je u praksi teško razlikovati. Nadodajmo tomu i činjenicu kako čovjek ništa ne čini bez interesa, tj. bez temeljne radoznalosti

4 U traženju odgovora na postavljeno pitanje služit ću se više antropologijom, etikom i sociologijom, a veoma malo teologijom. Taj izbor ne smije se shvatiti po logici više ili manje vrijedno ili važno, nego kao slobodni izbor u okviru naslova ovog razmišljanja.

5 U tumačenju razlikovnih pojmova (kao primjerice samopoštovanja) ograničavam se na nužno ako pridonosi jasnoći temeljnog pojma (sebičnosti).

6 Samosvijest trajno mora biti prožeta umjerenošću, inače se pretvara u samodopadnost ili narcizam, što neizravno vodi u sebičnost i isključivost, ili čak u samouništenje.

7 Obično se kulturi pridaju tri značenja: elitističko, pedagoško i etnologijsko. Prema elitističkom vidiku, kultura znači erudiciju. Kulturan je onaj koji posjeduje mnoge spoznaje, ili općenito ili u nekom području. U pedagoškom smislu, kultura znači odgoj: fizička kultura, moralna i duhovna kultura, kultura osjećaja itd. Etnologijski gledano, kultura je duhovna forma društva, sve ono što je ujedinjuje iznutra i ono što je razlikuje izvana od drugih kultura. Prema sva tri vidika, kultura je vrednota. Riječ je o instrumentalnoj, a ne apsolutnoj vrednoti (Mondin, 1985, 133-142).

8 Ne zaboravimo kako je termin vrednota, koji se danas rabi u teologiji i etici, preuzet iz ekonomije od analognog termina vrijednost. Prije tog ,posvojenja“ u teologiji i etici rabio se termin krepost. Vrijednost u ekonomiji nešto je što se može mjeriti količinski ili izraziti nominalno, valutom. Međutim, osim količinskog vredovanja (mjerenja) postoji i kvalitativno vrednovanje, tj moralno vrednovanje (vrednota), koje se redovito primjenjuje u specifičnom slučaju kreposti ili kvalitetā. Hrvatski jezik razlikuje vrijednost (količina) od vrednote (moralna kvaliteta), o čemu moramo voditi računa. 
koja ga pokreće i potiče na izbor i na djelovanje. Što će čovjek slobodno izabrati i kojim će se vrednotama (hraniti i) voditi kako bi postigao željeni cilj, ovisi isključivo o njemu samom. Slobodan je izabrati i slijediti velikodušnost i otvorenost (solidarnost i opće dobro) prema drugima ili isključivost i zatvorenost pred drugim, tj. sebičnost. U tom smislu opravdano je govoriti o različitim kulturama, koje se danas promiču, pa tako i o kulturi sebičnosti.

Naše razmišljanje polazi od uvjerenja kako je sebičnost, u negativnom smislu, dio ljudske naravi i zato treba biti stavljena u red. Je li čovjek po naravi sebičan? Odgovori se razlikuju: od potvrde do nijekanja. Prema mišljenju Barbare Di Salvo, riječ je o nečem neizbježnom i sastavnim dijelom ljudske naravi i dnevnog života te stoga ne predlaže borbu protiv sebičnosti, nego iskorištavanje „snage“ sebičnosti u pozitivnom smislu. Uostalom, sebičnost je »čudo života u borbi protiv smrti«, koju svaki čovjek dnevno vodi (Di Salvo, 2014, 104; Rand, 2003). Možda bi se mogla i prihvatiti ta tvrdnja ako bi se odnosila na duhovnu stvarnost, jer borba protiv sebičnosti znači borba protiv duhovne smrti. Ako pak ostanemo na fizičkoj razini, čini se kako je sebičnost strukturalna karakteristika prirođena čovjeku ako je očitovanje njegova instinkta preživljavanja. U pozitivnom smislu, dakle, sebičnost ne mora nužno značiti ego-centrizam, nego naravnu samousmjerenost u obrani vlastitog dobra. ${ }^{9}$ Ne zaboravimo kako nije riječ o etičkom prosuđivanju ili moralnom vrednovanju, nego o uočavanju postojanja određene stvarnosti, osobito prisutne na gospodarskom području.

Sljedeće je pitanje, kao logički slijed prethodnog: može li se sebičnost tumačiti kao pozitivnu ili pokretačku snagu, kao nešto što ide u prilog čovjeku? Uz već rečeno, smatram da bi odgovor mogao biti djelomično potvrdan. Ako se pod sebičnošću misli na naravne čovjekove potrebe — obrana vlastitog života, održavanje vrste, prehrana - mogli bismo govoriti o nekoj vrsti „pozitivne naravne sebičnosti“ koja je izričaj čovjekove naravi, a ne slobodnog izbora. Istodobno, treba dodati činjenicu da je čovjek, po naravi, društveno, relacijsko biće. Treba drugoga, njemu sličnoga, kako bi rastao, razvijao se, dozrijevao kao osoba. Drugi je za njega granica djelovanja i onaj koji ga stavlja u položaj uzajamnog poštivanja. Drugim riječima, moj bližnji je kriterij vrednovanja i ograničavanja moje sebičnosti: sebičnost jednoga ograničena je sebičnošću drugoga, tj. slobodni izbor jednoga uvjetovan je slobodnim izborom drugoga (Dawkins, 1992). ${ }^{10} \mathrm{U}$ tom kontekstu, primjerice s ekonomskog stajališta kapitalističkog sustava, moglo bi biti prihvatljivo takvo razmišljanje u smislu tolerirane, podnošljive konkurencije koja potiče na borbu za stjecanje što više, ali istodobno temperira (ublažava) vlastitu želju za više, od straha da bi drugi mogao biti uspješniji. Susreću se dvije jednake „sebičnosti“, ili ekonomskim rječnikom konkurencije, koje jedna drugu

9 Općenito se ego-centrizam određuje kao uvjerenje kako je vlastiti način postojanja, osjećanja i prosuđivanja apsolutno jedino moguć i valjan. Takvo uvjerenje određuje ponašanje. Kao i u slučaju sebičnosti, individualizma i solidarnosti, uvijek se misli, ne toliko na pojmovnu razinu, koliko na praktične stavove i ponašanje.

10 Za bolje razumijevanje iznesenoga usp. Dawkins 1992. 
istodobno potiču i ograničavaju. ${ }^{11}$ Istini za volju, navedena tolerirana konkurencija prestaje biti konkurencija i pretvara se u natjecanje ili kompetenciju, koja u nastojanju za više ne isključuje drugoga. ${ }^{12}$

Nakon rečenoga, očito je kako je sebičnost - po sebi i u sebi, po naravi i sadržaju — negativna sastavnica ili oznaka ljudskog izbora i djelovanja. Svaki pokušaj opravdavanja sebičnog ponašanja, ponajprije na ekonomskom području, nije vjerodostojan i uvjerljiv da bi mogao biti prihvaćen kao načelo djelovanja u duhu uzajamnog poštivanja i pravednosti. ${ }^{13}$ Nastojati „približiti“ ili ublažiti sebično ponašanje s ,potrebom“ razvijanja vlastitih sposobnosti i talenata u svakodnevnoj borbi za preživljavanje niti je uvjerljivo niti vodi dobru, bilo osobnomu bilo općemu. Nadalje, budući da je sebičnost zatvorenost u „vlastito dvorište“ protiv drugoga, takva situacija izaziva sumnjičenje, zavist, netrpeljivost i sukobe koji postaju sve oštriji i isključiviji ako se predstavljaju kao nova i opravdana ideologija. Nakon tog „ping-pong“ govora o sebičnosti i kulturi sebičnosti, jedini je zaključak koji se nameće snagom iznesenoga kako su vjerodostojna kultura i sebičnost nespojivi, osim ako prihvatimo i slijedimo trend i modu kulturā postmodernog društva. Jedno isključuje drugo. Konačno, već citirani Zygmunt Bauman, nedavno preminuli sociolog i filozof, glasno razmišljajući o opravdanim i izazvanim ograničenjima pred kojima suvremeni čovjek zatvara oči — stavljajući glavu u pijesak kako ih ne bi vidio - među ostalima navodi i različite oblike sebičnosti koji su toliko srasli s našim življenjem da ih prihvaćamo kao dio našeg bića. Zbog toga, veoma je teško jamčiti budućnost u kojoj bismo se ostvarivali kao ljudi, jer pred sobom vidimo samo sebe (i vlastiti probitak), a ne i drugoga u njegovoj cjelovitosti (Bauman, 2016, 22). ${ }^{14}$

Sve do sada izrečeno moglo bi se sažeti u tvrdnju: kultura sebičnosti u sebičnom društvu. Sebično društvo posljedica je kulture koja promiče sebičnost, tj. ljudi koji se odlučuju za sebičnost. Riječ je o dva čimbenika koji se istodobno potvrđuju. Talijanski sociolog i filozof Umberto Galimberti smatra kako je naše društvo »atomističko, individualističko i sebično«. Upravo to posljednje likuje prodrijevši u sva područja privatnog i javnog života (Minardi, 2017, 64).

11 Takav način razmišljanja nalazi uporište, između ostaloga, i u biologizmu Richarda Dawkinsa, kojim su ekonomisti nastojali protumačiti i opravdati kapitalističku konkurencijsku logiku (Dawkins 1992).

12 U svakom slučaju, određeni stupanj sebičnosti prisutan je u procesu natjecanja, koji se međutim ne može poistovjetiti ili svesti na odstranjivanje ili eliminaciju ekonomskog protivnika, što je u konačnici bitna oznaka konkurencije.

13 Posljedice sebičnog ponašanja na gospodarskom području vidljive su svima. Upravo je sebičnost jednih u temelju i razlog duboke podjele na bogate i siromašne kao očitovanja nejednakosti, nepravde, isključivosti i nepoštivanja.

14 Ograničenja se odnose na: »sljepoću ili obijest prirode unutar i izvan nas, ravnodušnost ili surovost bližih i dalekih ljudi, zlokobne i neočekivane posljedice naših pogrešnih predviđanja i naših pogrešaka i sebičnosti«. (Talijanski prijevod s izvornika na engleskom): »La cecità o i capricci della natura dentro o fuori di noi, l'indifferenza o l'asprezza di altri esseri umani a noi vicini o distanti, e le conseguenze disastrose inattese dei nostri calcoli sbagliati e dei nostri errori ed egoismi.« 
Još u vezi sa sebičnošću želim pripomenuti sljedeće: Pregledavajući i čitajući crkvene dokumente, osobito one koji čine corpus društvenog nauka Crkve, rijetko se govori zasebno o sebičnosti, nego redovito zajedno s drugom natuknicom, primjerice, s dostojanstvom osobe, sa zajedničkim dobrom, sa solidarnošću, s velikodušnošću, s individualizmom itd. Sebičnost ne nalazimo zasebno ni u Kompendiju društvenog nauka Crkve. Drugim riječima, sebičnost i kultura sebičnosti plod su vrste vrednota za koje se čovjek odlučuje. Drugi vatikanski sabor govori izričito o sebičnosti ili, točnije, o vrstama sebičnosti, samo u konstituciji Gaudium et spes. Glavni je razlog u prirodi sebičnosti o kojoj smo prije govorili. Iako je sebičnost nutarnja oznaka čovjeka, sebičan se, naime, može biti u odnosu na nekog ili na nešto (Cucci, 2008). Već spomenuta konstitucija Gaudium et spes podsjeća nas na trostruku razinu sebičnosti: individualnu, kolektivnu i nacionalnu (GS 25, 83 i 8c). ${ }^{15}$ Prvo se odnosi na uvjerenje ili stav, a drugo na djelovanje koje se pretvara u trajnu sukobljenost (Di Salvo, 2014, 21). Sebičnost, utjelovljena u kulturu sebičnosti izaziva sukobe u međudjelovanju, koje prati sva područja svakodnevnog života, osobnog i javnog. ${ }^{16}$ Samo po sebi postavlja se pitanje nadilaženja sukoba: je li moguće i na koji način? Ili još točnije: želimo li uistinu promjenu ${ }^{17}$ Čini se kao da smo izabrali (ili biramo) vrtjeti se u krugu iz kojeg ne želimo izići: bezvoljni prema svima i svačemu.

\section{Napor oko kulturalnog formiranja?}

Unutar sintagme kultura sebičnosti usredotočimo se na pojam kulture, kako bi bolje razumjeli njezin odnos (spojivost ili nespojivost) sa sebičnošću. Sadržaj

15 Individualna sebičnost: »Sigurno je da neredi, koji su tako česti u društvenom životu, djelomično dolaze od napetosti koje nastaju zbog ekonomskih, političkih i društvenih struktura. No dublji njihovi korijeni jesu ljudska sebičnost i oholost, koje kvare također i društvenu sredinu « (GS 25c). Izvori zla u društvu, dakle, proizlaze »iz pohlepe za vlašću i prezira prema osobama [...], nepovjerenja, oholosti, i drugih sebičnih strasti« kao, primjerice, »ljudske zavisti, nepovjerenja « (GS 83). Kolektivna sebičnost: Govoreći o neuravnoteženostima modernog svijeta, u Gaudium et spes čitamo: »Velika trvenja nastaju također između rasa, štoviše između različitih slojeva u društvu, između naroda u izobilju i onih koji su slabi i trpe oskudicu; konačno, između međunarodnih ustanova koje su nastale iz težnje naroda za mirom i propagandne nametljivosti vlastite ideologije ili kolektivnih egoizama unutar nacija i drugih skupina« (GS 8c). Nacionalna sebičnost: Govoreći o zauzetosti i promicanju mira u svijetu, nacionalne vlade i državnici moraju »svoj um i srce raširiti preko granica vlastite zemlje «, napustiti nacionalni egoizam i pohlepu da gospodare drugim narodima (GS 82b). Sebičnost je, dakle, „bolest“ koja se širi od pojedinca na skupinu, narod, svijet po zakonu spojenih posuda.

16 Po mojem sudu, trenutačna politička situacija u Republici Hrvatskoj plod je pojedinačne i stranačke sebičnosti. Drugim riječima, samovoljno stvaramo i biramo vrednote. Svi — pojedinci i stranke - vrte se u krugu svojih sebičnih interesa te, nošeni željom za vlašću, u trajnom su sukobljavanju koje im onemogućuje vidjeti i raditi za opće dobro. Kolektivna i pojedinačna sebičnost (prema pojedinačnim i stranačkim interesima) proglašava se „promicanjem općeg dobra“ ili „zaštitom države“. Država se poistovjećuje sa strankom pripadnosti koja, slijedeći vlastitu ideologiju, isključuje svakoga, pa i samu državu: država služi stranci.

17 Mislim, prije svega, na stanje inercije (mlitavosti i pasivnosti) u koje smo dovedeni sustavnim obezvređivanjem dobra (osobito od strane predstavnika vlasti), što nas sili slijediti etiku koristi i ugodnosti. 
kulture su vrednote, što znači, kako smo već spomenuli, vrsta kulture ovisi o vrsti vrednotā za koje se odlučujemo. Vrednote, a posljedično i kultura, postoje samo u odnosu na „slobodna i inteligentna bića“ i stoga su one (vrednote) »dobre stvari, koje doprinose rastu i usavršavanju osobnosti« (Örsy, 1987, 471-483). To razlučivanje i izbor događaju se na svim čovjekovim razinama: biologijskoj, psihologijskoj, intelektualnoj i duhovnoj (Dweyer, 1994, 961). Kad je riječ o kulturi i vrednotama uopće, pretpostavljam kako svi, manje ili više, misle o pozitivnim stvarnostima. Potrebno je, ipak, znati kako je kultura instrumentalna vrednota, što u odnosu na svrhu može biti i pozitivna i negativna. Ako, naime, kultura »nastoji ostvariti loše ciljeve u sebi, ili tzv. drugotne ciljeve koji su postali prvotni, apsolutni (...) tada više nije pozitivna « (Mondin, 1985, 133-134). U tom slučaju »ne promiče više vrednote, nego ne-vrednote«. Danas, kao i u prošlosti, postoje kulture koje se grade »na potpuno lažnim projektima o čovjeku, koje ne mogu, nikako i nikada, biti prihvaćene i promicane. To su svi projekti - materijalistički, hedonistički i znanstveni - koji čovjeku niječu duhovnu dimenziju « (Mondin, 1985, 134). Kulture koje prihvaćaju i promiču takve projekte o čovjeku suprotne su ljudskoj kulturi. Jasno je kako kulture lažnih projekata o čovjeku »uzimaju u obzir samo ekonomske, tjelesne, zemaljske i materijalne vrednote koje vode nazadovanju, slabosti i podivljalosti čovjeka i društva« (Mondin, 1985, 135).

Kultura, dakle, kao instrumentalna vrednota mora biti usmjerena čovjeku, apsolutnoj vrednoti jer, samo promičući dobro čovjeka kao čovjeka (osobe) kultura nalazi svoj raison d'être. Ono što se danas događa moglo bi se opisati kao relativiziranje čovjeka kao apsolutne vrednote i apsolutiziranje kulture kao instrumentalne vrednote. U tom kontekstu moguće je govoriti o kulturi sebičnosti koja samu sebe opravdava samo na razini učinkovitosti u duhu već rečenoga. Spomenimo samo primjer tzv. kulture smrti, kulture uživanja, kulture slobodnog vremena, kulture feminizma, kultura Wall-Streeta, kultura mršavljenja, kulture odbačenosti (izdvajanja) itd. U strogom smislu riječi, govor je o surogatima (nadomjescima, zamjenama) koje imaju malo ili nimalo zajedničkoga s kulturom ili, štoviše, protivne su joj. Istinska kultura promiče stvarno cjelovito dobro integralnog čovjeka, a kultura sebičnosti promiče samo materijalni dio čovjeka ili, u krajnjem slučaju, jednu od njegovih dimenzija koja se predstavlja kao „vjerodostojna" i kao takova se apsolutizira na štetu cjelovitosti osobe. ${ }^{18}$

Ako je to točno, onda je isto tako ispravno tvrditi kako kultura sebičnosti rađa sukobe. Zanemarujući duhovnu dimenziju u korist fizičke, narušava se sklad, cjelina koja se zove čovjek, osoba. Sklad se, naime, u čovjeku postiže samo poštujući i, istodobno, promičući njegovu cjelovitost, duh i tijelo, vertikalnu i horizontalnu dimenziju s pripadnim vrijednostima ili vrednotama (Katekizam 362). Kultura mora biti izričaj tog i takvog sklada i cjelovitosti jer u protivnom nije kultura ili,

18 Čitajući napisano, netko bi mi mogao prigovoriti kako materijalno blagostanje pomaže da se cjelokupni čovjek osjeća bolje? Bolje materijalno stanje doprinosi boljemu duhovnomu stanju? Nisam siguran u istinitost te tvrdnje, jer logično bi tada bilo da tko ima više automatski $i$ bude više, što nikako nije slučaj. Dakako, polazim od pretpostavke kako nije riječ o nužnim životnim potrebama čovjeka. 
kako imenuje Charles Taylor, duhovno izjednačavanje na istu razinu, koje praktično vodi do samo-nijekanja (Taylor, 2007, 524).

\section{Kulturom solidarnosti nadići kulturu sebičnosti}

Izloživši, u prvoj točki, nastojanje (težnju, pokušaje) suvremenog svijeta da sebičnost proglasi „vrednotom“ ili kulturom, koja kao takva vodi u sukobe i razaranje, logično je pitanje, je li moguće i kako nadići takvo stanje stvari? Odgovor je potvrdan. Ne samo da je moguće, nego i nužno. Jedan od načina „obraćenja“ sebičnosti je solidarnost, više kao (moralna) krepost nego načelo, i to kao trajno stanje otvorenosti za dobro drugoga ili, riječima Ivana Pavla II., kao »čvrsta i postojana odlučnost zauzeti se za opće dobro, to jest za dobro svih i svakoga, jer svi smo mi uistinu za sve odgovorni« (SRS 38d). ${ }^{19}$ Riječ je o habitusu koji postaje temelj kulture solidarnosti, koja po svojoj naravi teži suživotu u miru i u poštivanju drugoga. U tom smislu, riječ je o solidarnosti kao temeljnoj društvenoj kreposti (Mondin, 1985, 77-123; Kompendij 193c). ${ }^{20} \mathrm{U}$ već prije spomenutom opisu solidarnosti, spomenuli smo kako je ona otvorena za dobro drugoga. Drugomu željeti i činiti dobro znači poštivati ga i prihvatiti ga u njegovoj istosti i drugosti (različitosti). To i takvo osobno ponašanje mnogih pretvara se na društvenoj razini u mrežu relacija konkretiziranih u socijalnom ponašanju, to jest, u mirnom suživotu i suradnji svakoga i svih (Donati, 2015). Sebičnost, dakle, ili niječe te istinske odnose među ljudima ili ih svodi na utilitarističku dimenziju. Zatvaranje pojedinca u sebe (u svoju sebičnost) protivno je, dakle, i relacijskoj i društvenoj dimenziji ljudskog bića. Moramo nastojati prelaziti iz zatvorenosti u sebe prema otvorenosti drugomu, za što je potrebno vlastito nastojanje i povjerenje u drugoga. Ivan Pavao II. smatra kako je konkretni oblik otvorenosti drugomu praštanje (SRS 36; Bastianel, 1989, 15-38). U protivnom, opasnost je da se svakovrsne sebičnosti, koje drijemaju u pojedincu, probude i odvedu cijelo društvo na stranputicu (DM 14h; FC 21f, 33g i 37b).

Očito je, iz gore rečenoga, kako je čovjek po svojoj naravi otvorenost prema drugima čiji su izričaj svakodnevne međusobne relacije (pojedinaca i pojedinaca, pojedinaca i skupina), a koje mu pomažu da se ostvaruje kao biće za druge (De Rosa, 2007). Nije li takva tvrdnja u suprotnosti s djelovanjem čovjeka, koje je veoma često sebično, zatvoreno, isključujuće? Pierpaolo Donati, već citirani autor, na pitanje, što to znači da je ljudski život relacija, nudi prilično zadovoljavajući odgovor. Ideja ljudskog bića kao relacije vezana je s modernom..$^{21}$ Drugim riječima, cjelokupna ljudska stvarnost je relacijska (u relaciji). U

19 Glagol „zauzeti se“ treba shvatiti u neprekinutom trajanju i zato je bolje prevesti „zauzimati se“.

20 Kultura solidarnosti obuhvaća skup vrednota, kao primjerice ontologijske (vrijeme, prostor), osobne (osoba, tijelo, duh, seksualnost, sloboda, zvanje), društvene (obitelj, domovina, pravednost, mir), ekonomske (rad, tehnika) (Mondin, 1985, 77-123).

21 Povijesno gledano, počinje se s čovjekom kao zoon politikon, „politička životinja“ (Aristotel), što će romani nazvati „društvena životinja“, da bi se samo s modernom došlo do čovjeka kao relacijskog bića (Donati, 2015, 67). 
praksi, u konkretnom životu to zahtijeva odgovor na pitanje: što znači relacijski promišljati ljudski život u društvu? »Iako ljudi shvaćaju kako ljudski život znači boraviti (živjeti) u relacijama, imaju o tome većinom veoma ograničenu svijest « (Donati, 2015, 67-68).

Slijedi, dakle, kako kvaliteta ljudskog života ovisi o relacijskim odnosima, tj. o društvenim odnosima, kategorija koja je formulirana u moderno doba (Donati, 2015, 68-70). Govorimo o društvu, a ne pojedincu ili, točnije o relacijama među pojedincima, ali u društvu. Dvije su, dakle, temeljne stvarnosti: čovjek i društvo, pojedinac i kolektiv. I jedno i drugo mora se odgajati i formirati za relacijski život. Taj u sebi uključuje i subjektivne i objektivne elemente, tj. prostor gdje se susreću »bilo udaljenost bilo uključenost pojedinaca«, koji se nalaze u društvu (Donati, 2015, 70). Prostor je, dakle, nužan okvir u kojem se događaju društvene relacije koje podrazumijevaju društvene strukture i institucije. Drugim riječima, prostor ili društvo je »uobličavanje relacije koje se javljaju preko procesa u kojima možemo, analitički i iskustveno, razlikovati tri stupnja: društvenokulturalni i strukturalni oblici koji prethode ulasku pojedinca (u društvo), djelovanje subjekata-agenata koji se kreću u međusobnim relacijama uvjetovanih tim oblicima, i rezultati tih među-djelovanja, koje se mogu ponovno aktivirati ili promijeniti početne društveno-kulturalne strukture« (Donati, 2015, 72-73; Mathieu, 1000-1005). Drugim riječima, jedna društvena relacija uključuje instinktivne, afektivne i normativne elemente. Sva tri elementa ili dimenzije oblikuju se i očituju u jednom jedinom činu, društvenoj relaciji.

$\mathrm{S}$ obzirom na elemente društvene relacije (instinkt, osjećaji, norme), ne smijemo zaboraviti kako je riječ o svakodnevnoj čovjekovoj stvarnosti, o stvarnom svijetu u kojem čovjek živi. U današnjem modernom okruženju, zahvaljujući tehnologijskom napretku, u opasnosti smo da stvarno zamijenimo s virtualnim. Tehnologija nam omogućava da si stvaramo virtualni (lažni) svijet i u njemu živimo bez obzira na stvarnost. Događa se tako da sama relacija s drugim iz stvarnosti prelazi u virtualni svijet i virtualne, nestvarne, relacije. Ne može se više govoriti o relacijama i otvorenosti prema drugomu, nego o osobnoj usmjerenosti na sebe samoga i zatvorenosti prema stvarno drugomu. U tom kontekstu, više ni samog sebe ne doživljavam kao stvarnog (nesavršenog, slabog itd.), nego kao željenog ili zamišljenog (nestvarnog, lažnog, svršenog, sve-mogućeg). Tako sve i svi oko mene postaju virtualni, tj. lažni, kao rezultat virtualnih relacija i virtualne solidarnosti, jer virtualna relacija ne može dati društveni oblik ili formu našemu postojanju (životu, djelovanju) (Donati, 2015, 98-99). ${ }^{22}$

Ljudski život niz je relacija u gore opisanom smislu. Riječ je o mi-relacijama (we-relation): moja relacija prema tebi i tvoja relacija prema meni čine mi-relaciju, koja se ostvaruje u prihvaćanju i uzajamnom poštivanju (Donati, 2015, 104; Cusinato, 2013; Archer, 2016). Taj tip relacija, jednom institucionaliziran, čini

22 Opasnost širenja ovisnosti o tehnologiji (Internetu itd.) ne smije se shvatiti po logici bijelo-crno. Snaga tehnologijske zavodljivosti treba biti disciplinirana ispravnom i trajnom formacijom u duhu ljudskih i kršćanskih vrijednosti. 
jezgru struktura i institucija, ili bilo kojeg oblika javnog organiziranja. Govorimo o relacijama među ljudima, tj. subjektima s razumom i slobodnom voljom, koji odlučuju i biraju u skladu sa svojim osobnim dostojanstvom. Načelno to je točno i tako bi trebalo biti. Životna praksa, međutim, pokazuje velika odstupanja ili čak djelovanja protivna spomenutomu načelu. Ako mi-relacije ispunjaju osobni i ,zajednički“ grešni čini, one nisu više potvrda dostojanstva osobe, nego izravno i neizravno nijekanje istog dostojanstva. ${ }^{23}$

Nakon gore opisane relacijske dimenzije ljudskog bića, možemo se više usredotočiti na solidarnost koja se predstavlja kao uzvišeni oblik naravne relacijske dimenzije čovjeka. S tim izrazom želim upozoriti na čovjeka kao osobu, kao jedna u dvije dimenzije, horizontalnoj i vertikalnoj ili, drugim riječima, materijalnoj (fizičkoj) i duhovnoj. Relacijska dimenzija osobe - obdarene razumom i slobodnom voljom — oblikuje se i očituje kao solidarnost (s drugim) pod uvjetom poštivanja poretka vrijednosti. ${ }^{24}$ Tako shvaćena solidarnost protivi se bilo sebičnosti bilo individualizmu. ${ }^{25}$ Kao što se od sebičnosti stvara životna ideologija koja ne podnosi drugoga različitoga, tako življena solidarnost potiče na uzajamnu otvorenost i suradnju. U prvom slučaju skladni i uređeni društveni život nije moguć jer su sukobi trajno obilježje svakog razmišljanja i djelovanja, koja, u krajnjem slučaju, završavaju rastakanjem nužnog zajedništva te stvaranjem ozračja sukoba, netrpeljivosti i isključivosti s dalekosežnim posljedicama i za pojedinca i za cijelu zajednicu. U drugom slučaju, solidarnost među ljudima čini se jedinim načinom i putem prema čovjeku dostojnomu zajedništva.

Danas, više nego ikada, solidarnost se nameće kao imperativ i pojedincu i institucijama. Ona, prema prije spomenutoj odrednici, nalazi svoje opravdanje i svrhu u samoj čovjekovoj naravi kao razumskoj, društvenoj/relacionalnoj i religioznoj. Prema tomu, čovjekov izbor sebičnosti znači izbor protiv vlastite naravi, izbor prema samouništenju. ${ }^{26}$ Ponavljam, jedini način da se to ne događa

23 U tom slučaju govorimo o, već spomenutim, grešnim strukturama, gdje subjekti i cjelina ne prakticiraju uzajamno poštivanje i ne teže ostvarivanju općeg dobra. Korisno je ponovno se prisjetiti, kada je govor o grešnim strukturama, kako Crkva strogo razlikuje osobni grijeh od društvenog grijeha. Kompendij Društvenog nauka Crkve, pozivajući se na Ivana Pavla II., ističe kako se »otajstvo grijeha sastoji od dvostruke rane, koju grešnik otvara u sebi i u odnosima s bližnjim«.

24 Relacijsku dimenziju osobe, koja nalazi svoj izričaj u življenoj solidarnosti, ističu osobito pape Ivan Pavao II., Benedikt XVI. i Franjo u socijalnim enciklikama.

25 Mit o individualizmu temelji se na činjenici da društveni i kulturalni sustavi modernih društava jednostavno ne vide društvene relacije, ne smatra ih bitnima za društvenu stvarnost »nego ih smatra kao sekundarne entitete, koji ovise o pojedincima ili institucijama, i zato ih se može mijenjati po volji« (Donati, 2015, 84). O starom i novom individualizmu na političkom i filozofskom planu piše John Dewey (Dewey, 2013). O individualizmu kao trajnoj konstanti u ekonomsko-financijskom svijetu piše Luciano Gallino (Gallino, 2011).

26 Hartmut Rosa, njemački sociolog, izriče istu misao kao mnogostruko čovjekovo otuđenje: otuđenje od prostora, otuđenje od stvari, otuđenje od našeg vlastitog djelovanja, otuđenje od vremena, otuđenje od sebe samog i od drugih (Rosa, 2015, 98-114). Isti autor donosi misao sociologa Gergena Kennetha (The Saturated Self, 2000) koji proučava čovjekovu sebičnost kao rezultat tehnologijske pretjeranosti: »Preko suvremene tehnologije, broj i raznolikost relacija u koje smo uvučeni, moguća učestalost susreta, očitovana jakost relacija i trajanje u vremenu neprestano su se povećavali. Kada je taj rast došao do krajnosti, dostižemo učinak zasićenosti« (Rosa, 2015, 
življena je solidarnost utemeljena na uzajamnom poštivanju i zajedničkom naporu u promicanju osobnog i zajedničkog dobra. Uostalom, solidarnost kao načelo društvenog naučavanja Crkve, uvijek je u zajedništvu s drugim temeljnim načelima, primjerice poštivanjem osobe, subsidijarnosti i općeg dobra, kako nam to govore dokumenti društvenog naučavanja Katoličke crkve. Uostalom, nemoguće je poštivati drugoga i biti sebičan, ili živjeti solidarnost u sebičnosti. Nije moguće služiti dvojici gospodara (Mt 6, 24). To vidimo i svjedočimo svaki dan u svim područjima osobnog i društvenog života. Osjetljivi smo na sebičnost političara, privrednika, trgovaca, bankara, liječnika, svećenika itd., jer njihov je poziv biti nesebično u službi dobra drugih, svih građana. Sebičnost u navedenim i drugim područjima imenuje se kao pokvarenost ili korumpiranost, nepoštenje ili gramzljivost. Navedena zvanja zahtijevaju sklad između osobnog i javnog života u dosljednom traženju i provođenju dobra svih. U protivnom, i osoba i djelovanje postaju nevjerodostojni: bujica riječi i beskrajni govori i obećanja rasplinjuju se kao dim na vjetru. Manjak vjerodostojne solidarnosti rađa sukobe i jaz između građana i vladajućih skupina, što dovodi do bešćutnosti jednih i beznađa drugih, osobito na političkom i gospodarskom području.

Uvjeren sam kako je zajednički život moguć samo u uzajamnom poštivanju i solidarnosti. Svaki drugi put vodi u nijekanje vlastite naravi, u sukobe, razaranja. Ne smijemo zaboraviti kako je solidarnost kao »čvrsta i postojana odlučnost zauzimati se za opće dobro« proces, nikad dovršen, i izazov koji traži uvijek novi prikladan odgovor (SRS 38d). Kao što izbor kulture sebičnosti vodi u samouništenje, tako kultura solidarnosti vodi prema zajedništvu i općemu dobru.

\section{Literatura:}

Albani, Paolo (2016). „Siamo tutti stupidi tranne me e te“. U Domenica Il Sole 24 Ore, 9 ottobre, str. 27-28.

An. (1977). Dizionario delle idee. Firenze: Sansoni.

Archer, Margaret Scofford (2016). Normativity and Social Morphogenesis. New York: Springer.

Bastianel, Sergio (1989). Strutture di peccato: Riflessione teologico-morale. U: Sergio Bastianel (ur.), Strutture di peccato: Una sfida teologica e pastorale (str. 15-38). Casale Monferrato: Piemme.

Bauman, Zygmunt (2016). „L'uomo schiacciato dai limiti“. U: L'Espresso. Settimanale di cultura politica economia URL: http://espresso.repubblica.it/attualita/2016/11/04/ news/l-uomo-schiacciato-dai-limiti-1.287331 (29.06.2017.)

Bosanac, Milan; Mandić, Oleg; Petković, Stanko (1977). Rječnik sociologije i socijalne psihologije. Zagreb: Informator.

Boxel, Matthijs van (2008). The Encyclopaedia of Stupidity. Chicago: University of Chicago Press. 
Carriere, Jean-Claude; Eco, Umberto (2009). Non sperate di liberarvi dei libri. Rim: Bompiani.

Cucci, Giovanni (2009). Il fascino del male: I vizi capitali. Rim: Apostolato della Preghiera Edizioni.

Cusinato, Mario (2013). La competenza relazionale: Perché e come prendersi cura delle relazioni. Milano: Springer.

Dawkins, Richard (1992). Il gene egoista. Rim: Mondadori.

De Rosa, Giuseppe (2007). L'uomo, la sua natura il suo destino: Antropologia cristiana. Rim: Elledici.

Dewey, John (2013). Individualismo vecchio e nuovo. Parma: Diabasis.

Di Salvo, Barbara (2014). In difesa dell'egoismo. Siveria Mannelli: Rubettino.

Donati, Pierpaolo (2015). L'enigma della relazione. Milano - Udine: Mimesis Edizioni.

Dweyer, Judith (ur.) (1994). The New Dictionary of Catholic Social Thought. Collegeville - Minesota: The liturgical Press.

Galimberti, Umberto (2017). Vivere da soli, il trionfo dell'egoismo. L'espresso: Settimanale di politica, cultura e economia, 27 gennaio, 64-65.

Gallino, Luciano (2011). Finanzcapitalismo: La civiltà del denaro in crisi. Torino: Einaudi.

Gergen, Kenneth (2000). The Saturated Self: Dilemmas of Identity in Contemporary Life. New York: Basic Books.

Katekizam (1992). Catechismo della Chiesa Cattolica. Città del Vaticano: Libreria Editrice Vaticana.

Kompendij (2005). Pontificio Consiglio della Giustizia e della Pace, Compendio della dottrina sociale della Chiesa. Città del Vaticano: Libreria Editrice Vaticana.

Michéa, Jean-Claude (2016). L'anima umana sotto il capitalismo, postfazione. U: Cornelius Castoriadis i Christopher Lasch (ur.), La cultura dell'egoismo (str. 41-55). Città di Castello: Elèuthera - Caienna.

Minardi, Sabina (2017). É il trionfo dell'egoismo: Colloquio con Umberto Galimberti. L'Espresso, Settimanale di politica e cultura economia, n. ? 64-65.

Mondin, Battista (1985). I valori fondamentali: Definizione e classificazione deo valori. Rim: Dino Editore.

Odifreddi, Piergiorgio (2016). Il dizionario della stupidità: Fenomenologia del non-senso della vita. Milano: Rizzoli.

Örsy, Ladislas (1987). The Relationship between Values and Laws. The Jurist, 47, 471-483.

Piemontese, Giuseppe (2015). Dal Capitalismo alla globalizzazione fra egolatria e alterità. L'Attacco di Foggia.

Rand, Ayn (2003). La virtù dell'egoismo. Macerata: Liberilibri.

Rosa, Hartmut (2015). Accelerazione e alienazione. Torino: Einaudi.

Taylor, Charles (2007). L'età secolare. Milano: Feltrinelli. 
From a Culture of Egoism toward a Culture of Solidarity

\section{Josip Jelenić*}

\section{Summary}

The author reflects on the phenomenon in contemporary society called the culture of egoism which has become the ideology of modern man. This ideology always excludes the other, the one who is different, because it is concerned with one-way egotistical activities based on domination. The result is division in society causing permanent conflict and ending, as a rule, in self-destruction. Instead of a culture of egoism, always ideology-based, a culture of solidarity is recommended as the way in which to live and work for one's personal and also the common good. Here solidarity is understood and accepted as a basic value which evolves into a principle and a mandatory course of action. After all, it is solidarity, and not egoism, which is the expression of the social nature of the human being.

Key words: egoism, culture, solidarity, conflicts, ideology, common good

* Professor Josip Jelenić, Ph.D., Full Professor, Pontifical Gregorian University, Rome. Address: Piazza della Pilotta 4, 00187 Rome, Italy. E-mail: jelenic@unigre.it 